\title{
Audiência de Custódia e Violência Policial: Análise do Encaminhamento das Denúncias em Duas Gestões na Cidade de São Paulo ${ }^{1}$
}

\author{
Custody Hearing and Police Violence: Analysis of the Handling \\ of Complaints in Two Administrations in the City of São Paulo
}

\section{Giane Silvestre}

Núcleo de Estudos da Violência, Universidade de São Paulo, São Paulo, SP, Brasil

Maria Gorete Marques de Jesus

Núcleo de Estudos da Violência, Universidade de São Paulo, São Paulo, SP, Brasil

\section{Ana Luiza Villela de Viana Bandeira}

Escola de Direito, Fundação Getúlio Vargas, São Paulo, SP, Brasil

\section{RESUMO}

Este artigo discute o encaminhamento institucional dado aos relatos de violência policial nas audiências de custódia realizadas na cidade de São Paulo, fazendo uma análise comparativa entre duas gestões na coordenação do projeto. As análises consolidam as trajetórias de pesquisas das autoras que, desde 2015 com a implantação do projeto, até 2020, com sua suspensão em decorrência da pandemia de Covid-19, coletam dados por meio de observação direta e de entrevistas com os operadores envolvidos nas audiências. As coletas foram realizadas em momentos distintos das duas gestões, possibilitando a observação das mudanças dos operadores, da visão sobre a finalidade da audiência e o seu impacto no tratamento das denúncias de violência policial no momento da prisão

1 Este artigo foi desenvolvido com o apoio da Fundação de Amparo à Pesquisa do Estado de São Paulo (FAPESP). Utiliza dados coletados nas pesquisas de pós-doutorado das autoras Giane Silvestre (processo n ${ }^{\circ}$. 2017/04428-6) e Maria Gorete Marques de Jesus. As pesquisas desenvolvidas integram o Programa CEPID/FAPESP Construindo a democracia no cotidiano: direitos humanos, violência e confiança institucional, desenvolvido pelo Núcleo de Estudos da Violência (NEV-USP), processo nº. 2013/07923-7. 
As análises apontam que a primeira gestão adotava procedimentos que pressionavam as corregedorias das polícias a investigarem as denúncias relatadas em audiência, ainda que a eficácia de tais medidas seja questionável. Já a segunda gestão mudou o procedimento de encaminhamentodasdenúncias, adotandoacomunicaçãodiretaàsrespectivascorregedorias de polícia, sem que haja acompanhamento ou pressão por apuração. Concluímos que a visão que o gestor possui sobre a política criminal e a finalidade da audiência em si, bem como a fragilidade institucional das audiências, influenciam diretamente os seus objetivos e resultados, evidenciando assim os limites do instituto das audiências de custódia.

Palavras-chave: Audiências de Custódia, Violência Policial, Política Criminal, São Paulo, Juízes.

\section{ABSTRACT}

This article aims to discuss the institutional approach given to reports of police violence in custody hearings held in the city of São Paulo, making a comparative analysis between two different administrations. The analyzes consolidate the research trajectories of the authors who, since 2015, with the implementation of the project, until 2020, with its suspension due to the Covid-19 pandemic, collected data through direct observation and interviews with the operators involved in the hearings. The collections were carried out at different times between the two administrations, making it possible to observe the changes in the operators, the view on the purpose of the hearing and its impact on the treatment of complaints of police violence at the time of arrest. The analyzes indicate that the first management adopted procedures that put pressure on the police departments to investigate the complaints reported at the hearing, even though the effectiveness of such measures is questionable. The second management, on the other hand, changed the procedure for forwarding complaints, adopting direct communication to the respective police internal affairs, without monitoring or pressure for investigation. It is concluded that the view that the manager has, both on criminal policy and on the purpose of the hearing itself, as well as the institutional fragility of the hearings, directly influences its objectives and results, thus evidencing the limits of the custody hearings institute itself.

Keywords: Custody Hearings, Police Violence, Criminal Justice, São Paulo, Judges.

\section{APRESENTAÇÃo}

A audiência de custódia é uma inovação que, desde 2015, vem sendo incorporada ao processo criminal por iniciativa do Conselho Nacional de Justiça (CNJ). Consiste na apresentação da pessoa presa em flagrante em 24 horas diante do juiz, do promotor e da defesa, que 
pode ser representada por defensor público ou advogado. Tem como objetivo principal averiguar a necessidade de manutenção da prisão, a sua legalidade e a apuração de relatos de abusos e violência policial. Em 2015, as primeiras audiências do país foram realizadas na cidade de São Paulo, no Fórum Criminal Ministro Mario Guimarães, situado no bairro da Barra Funda. Começaram como um projeto piloto, que envolveu uma articulação entre o CNJ, o presidente do Tribunal de Justiça de São Paulo, o Secretário de Segurança Pública e o Juiz Corregedor do Departamento de Inquéritos policiais (DIPO) ${ }^{2}$. Na época, entendeu-se que o Departamento que funciona dentro do Fórum desde 1985 apresentava uma estrutura facilitadora das audiências de custódia, já que reunia juízes destacados para a função de avaliar os autos de prisão em flagrante e decidir sobre medidas cautelares.

Mesmo com a estrutura institucional favorável, uma série de adaptações foram necessárias para criar a estrutura física para a realização das audiências, tais como prover salas, organizar o fluxo e a distribuição dos autos de prisão em flagrante pelo cartório, acomodar os profissionais do Instituto Médico Legal (IML), visando a realização de exames periciais e gerenciar o fluxo das pessoas que circulavam pelas audiências. A construção de todo este aparato exigiu empenho e vontade política dos atores envolvidos à época. Havia também uma preocupação sobre o encaminhamento dos relatos de violência policial, sobretudo porque a implementação das audiências de custódia teve como grande argumento a oportunidade de apurar supostas práticas de tortura. Assim, criou-se um procedimento de concentrar tais casos no DIPO 5, que é uma das cinco subdivisões do DIPO (BANDEIRA, 2020).

Passados cinco anos do processo de implementação, as audiências de custódia tornaram-se realidade não apenas em São Paulo, mas em todo o país. No caso da capital paulista, hoje contam com espaço mais adaptado, com fluxo mais consolidado e normatizado nas rotinas do Fórum. Contudo, uma mudança na gestão do DIPO, ocorrida em 2018 impactou em alguns procedimentos adotados pela coordenação anterior. Uma dessas mudanças foi a alteração nos procedimentos em casos de denúncia de violência policial, que deixaram de ser encaminhados ao DIPO 5 e passaram a ser diretamente comunicados às respectivas Corregedorias da polícia denunciada.

Diante deste contexto, este artigo discute o encaminhamento institucional dado aos relatos de violência policial nas audiências de custódia realizadas na cidade de São Paulo, após a mudança na coordenação do projeto, bem como o arranjo político institucional do DIPO, onde as audiências estão alocadas. As análises consolidam as trajetórias de pesquisas das autoras

2 Mais adiante será explicada e analisada a estrutura do DIPO no contexto da justiça criminal em São Paulo. 
que, desde 2015, com a implantação do projeto, até 2020, com sua suspensão em decorrência da pandemia de Covid-19, coletam dados por meio de observação direta e de entrevistas com os operadores envolvidos nas audiências.

$\mathrm{O}$ artigo está dividido em quatro seções, além desta apresentação. A primeira traz a metodologia adotada e a descrição do processo de coleta de dados, bem como os seus instrumentos. A segunda apresenta uma descrição das duas gestões, levantando as principais questões ligadas ao arranjo institucional do DIPO e as consequências da mudança na coordenação das audiências. A terceira seção trata do encaminhamento das denúncias de violência policial realizada por ambas as gestões, destacando as suas diferenças e singularidades, trazendo relatos dos atores que experienciaram a primeira gestão e aqueles que seguem atuando na segunda gestão. Ao final, destacamos os principais pontos discutidos no texto, mostrando como a visão que o gestor possui sobre a política criminal e a finalidade da audiência em si, bem como a fragilidade institucional das audiências influenciam diretamente os seus objetivos e resultados, evidenciando assim os limites do instituto das audiências de custódia.

\section{METODOLOGIA}

O artigo apresenta uma reflexão comparativa de experiências de pesquisa nas audiências de custódia da capital paulista. As autoras realizaram trabalho empírico para diferentes pesquisas, em momentos distintos: 2015, 2016, e 2019³. A pluralidade das incursões no campo permitiu observar, na prática, as mudanças implementadas pela troca de gestão do Departamento de Inquéritos Policiais em 2018. O trabalho empírico consistiu em coleta de dados predominantemente qualitativos, por meio da observação das audiências e das interações entre os diferentes atores, e entrevistas.

As observações das audiências seguiram o critério da aleatoriedade de modo que as pesquisadoras puderam fazer um revezamento entre as 11 salas de audiência, presenciando a atuação dos diferentes juízes. Assim, foi possível acompanhar a atuação de quase a totalidade

3 As pesquisadoras realizaram trabalho de campo em determinados períodos dos anos mencionados e não ao longo do ano todo. Como resultado dessa trajetória de pesquisa empírica, foram produzidas uma dissertação de mestrado (BANDEIRA, 2018), uma tese de doutorado (JESUS, 2016), dois relatórios de pesquisa de abrangência nacional (CNJ/FBSP, 2017; IDDD, 2016), um relatório de pesquisa de abrangência local (NEV/CEPID, 2020) e um artigo científico (SILVESTRE; JESUS; BANDEIRA, 2020). 
dos juízes nas duas gestões analisadas ${ }^{4}$. As observações foram registradas em caderno de campo e analisadas em conjunto, destacando aspectos como a relação entre juiz e custodiado, juiz e defesa, juiz e promotor, bem como a interação entre os demais atores que influenciam direta ou indiretamente a condução da audiência, especialmente policiais militares.

Além das observações, durante a gestão que compreende o período de 2015 a 2018, também foram realizadas entrevistas semiestruturadas com juízes, defensores e promotores. Já em 2019, período da segunda gestão, as pesquisadoras entrevistaram presencialmente a atual juíza corregedora. Em 2020 foram entrevistados defensores de forma remota, por meio da plataforma Zoom, já que as audiências de custódias foram suspensas e medidas de distanciamento social foram implementadas em todo o país devido à pandemia de Covid-19. Além disso, também foi realizada uma entrevista remota com o ex-juiz corregedor do DIPO. Todas as entrevistas foram transcritas e analisadas em conjunto para recompor o histórico de implementação das audiências, bem como explorar as percepções dos atores em relação às diferenças entre as gestões, com destaque para o encaminhamento das denúncias de violência policial.

Além dos dados primários coletados nas audiências de custódia e em entrevistas com operadores, este artigo também buscou textos, entrevistas e falas públicas da atual juíza corregedora DIPO e de seu antecessor, na imprensa e nos portais especializados em direito. Buscou com isso remontar o processo de troca da gestão e dar destaque às percepções e manifestações públicas desses atores sobre os objetivos e resultados das audiências. O texto analisa ainda as estatísticas divulgadas pelo CNJ referentes ao percentual de manutenção das prisões, concessão de liberdade provisória e denúncia de violência policial, além de dialogar com a bibliografia produzida recentemente acerca do tema.

\section{AUDIÊNCIAS DE CUSTÓDIA EM SÃO PAULO: 0 DIPO E SUAS GESTOES}

No ano de 2015, o CNJ passou a firmar parcerias com os Tribunais de Justiça estaduais para a implementação das audiências de custódia em todo o país. Como exposto na apresen-

4 Houve trocas pontuais de juízes em períodos em que as pesquisadoras não estavam em campo, porém a maior parte da equipe foi mantida, possibilitando a observação da atuação de quase todos os juízes. 
tação, essas audiências consistem na apresentação de pessoas presas em flagrante a um juiz no prazo de 24 horas após a prisão, com o objetivo de averiguar a necessidade da manutenção da prisão ${ }^{5}$. A implementação das audiências de custódia se deu em cumprimento à Convenção Americana sobre Direitos Humanos (Pacto de San Jose da Costa Rica), da qual o Brasil é signatário ${ }^{6}$.

Para a regulamentação das audiências no país, o CNJ elaborou a Resolução 213 de 2015 que estabelece os protocolos e procedimentos a serem adotados no rito jurídico ${ }^{7}$. Além de avaliar a necessidade da manutenção da prisão, a audiência tem a função de apurar situações de violência, maus-tratos e tortura praticadas por agentes do Estado durante a detenção. Em audiência são ouvidos o Ministério Público, a Defensoria Pública ou o advogado particular.

É importante ressaltar também que, em 2015, foi criado o Sistema de Audiência de Custódia (SISTAC), com o intuito de coletar os dados resultantes das audiências realizadas no Brasil e monitorar sua implementação, mas com acesso restrito aos operadores das audiências. O Portal congrega os dados das decisões, que são alimentados pelos próprios Tribunais de Justiça estaduais. Apesar de simbolizar um esforço institucional grande em reunir os dados de prisão em flagrante, o sistema é utilizado apenas pelos operadores e os dados disponibilizados ao público ainda dependem de publicação específica do CNJ.

Antes da implementação das audiências de custódia, os juízes analisavam apenas o auto de prisão em flagrante para averiguar sua legalidade e, com base exclusivamente nesse documento, decidiam se havia a necessidade de manutenção da prisão. Neste sentindo, é possível afirmar que as audiências vêm para reforçar o caráter acusatorial do processo penal brasileiro, numa fase em que a inquisitorialidade predominava para a maior parte dos acusados, como bem mostrou a literatura da área (KANT DE LIMA, 1995; PAES, 2013; MISSE et al., 2010).

O projeto piloto na capital paulista, que teve início em 2015, tinha como objetivo "testar" a implementação do instituto na cidade com o maior número de prisões em flagrante diárias. Acreditava-se que, caso o projeto fosse bem-sucedido em São Paulo, certamente teria êxito em todos os lugares do Brasil. É importante destacar que, por conta da magnitude da esfera

\footnotetext{
5 Vale mencionar que, de acordo com o artigo 312 do Código de Processo Penal brasileiro, a prisão preventiva é necessária somente nos casos em que há ameaça à ordem pública ou à ordem econômica, por conveniência da instrução criminal ou para assegurar a aplicação da lei penal, quando houver prova da existência do crime e indício suficiente de autoria e de perigo gerado pelo estado de liberdade do imputado. Disponível em: http://www.planalto. gov.br/ccivil_03/decreto-lei/del3689.htm\#art312. Acesso em: 04 ago. 2020.

6 Disponível em: http://www.planalto.gov.br/ccivil_03/decreto/D0678.htm. Acesso em: 29 jul. 2020.

7 Disponível em: https://www.cnj.jus.br/wp-content/uploads/2019/04/resoluo-n213-15-12-2015-presidncia.pdf. Acesso em: 29 jul. 2020.
} 
criminal em São Paulo, desde 1985 existe um departamento exclusivamente destinado a processar os autos de prisão em flagrante e os inquéritos policiais da capital: o Departamento de Inquéritos Policiais (DIPO).

Muito anterior ao advento das audiências de custódia, o DIPO é uma estrutura que existe apenas na cidade de São Paulo e, atualmente, sua constitucionalidade é objeto de discussão. O DIPO é subdividido em cinco departamentos, gerido por um juiz corregedor, e possui juízes fixos designados por ele que, por sua vez, é indicado pelo Corregedor-Geral do Tribunal de Justiça. O critério de seleção dos juízes que integram o DIPO não é público e nem tampouco transparente, ainda que em 2013 a Lei Estadual n 1208 tenha estabelecido procedimentos mínimos para a nomeação de juízes, tais trâmites não têm sido observados ${ }^{8}$.

Desta forma, na cidade de São Paulo, ao contrário do que ocorre no restante do país, mesmo antes das audiências de custódia, o auto de prisão em flagrante não era apreciado pelo juiz da vara, mas sim pelo juiz do DIPO. Esta estrutura parece estar em dissonância, ao mesmo tempo, com o princípio do juízo natural (art. $5^{\circ}$ inc. XXVII da CF) e com a prerrogativa da inamovibilidade (art. 95 inc. II da CF) e, não por acaso, é contestada no Supremo Tribunal Federal (STF) em uma ação da Defensoria Pública do Estado de São Paulo9. Nesse sentido, o DIPO, como bem destacou Kuller (2017, p. 73), pode ser visto como um departamento político dentro judiciário em que as orientações políticas conferem fragilidade à independência funcional e ao princípio do livre convencimento.

É preciso compreender o DIPO enquanto dispositivo político estratégico dentro do arcabouço institucional do judiciário e que está articulado com outras instâncias e dinâmicas políticas. Portanto, compreender o funcionamento das audiências de custódia pressupõe considerar os arranjos institucionais dos quais fazem parte, bem como as assimetrias que possivelmente marcam a relação entre os atores que compõem a cena. (KULLER, 2017, p. 74).

Mesmo diante deste complexo arranjo institucional (ou talvez justamente por isso), o DIPO foi o local escolhido pelo CNJ para iniciar o projeto das audiências de custódia. Em 2015, o DIPO possuía nove juízes fixos e quatro defensores públicos que trabalhavam exclusivamente

8 Não há publicações do Tribunal de Justiça sobre os critérios utilizados para alocações internas. Em entrevistas com os juízes, no entanto, foi mencionado que a escolha depende primordialmente da afinidade pessoal do juiz corregedor responsável pelo DIPO.

9 Em 2018, a Defensoria Pública do Estado de São Paulo entrou com um pedido liminar de cassação das nomeações no DIPO, com base na inobservância da garantia do juízo natural, do princípio da inamovibilidade e do descumprimento da Lei estadual 1208/2013. Ver: https://www.conjur.com.br/dl/defensoria-cassacao-dipo.pdf. Acesso em: 04 ago. 2020. 
na análise dos flagrantes trazidos pela autoridade policial. Além de ter sido encampado pessoalmente pelo então Presidente do Tribunal de Justiça de São Paulo, Desembargador Roberto Nalini, o projeto também encontrou respaldo junto ao juiz que, à época, ocupava o cargo de corregedor do DIPO, Antonio Patiño, que se tornou responsável pela operacionalização das audiências no fórum.

O respaldo institucional dado às audiências de custódia (tanto pelo poder judiciário quanto pelo executivo) em São Paulo foi fundamental não apenas para colocar o projeto em prática, mas também para a reorganização do espaço físico do Fórum Criminal. No início do projeto, as salas de audiência foram adaptadas em um antigo Plenário do Tribunal do Júri. Em fevereiro de 2016, as obras do novo espaço no Fórum ficaram prontas e as audiências de custódia ganharam lugar próprio: 11 novas salas de audiência foram construídas, além de salas específicas para a Defensoria Pública, Ministério Público e IML; o cartório foi ampliado e os presos em flagrante passaram a ficar em uma nova carceragem própria, diferente dos presos que chegavam para outras audiências.

O juiz e ex-corregedor do DIPO coordenou toda estruturação física do Fórum Criminal para receber as audiências de custódia acabou se tornando um defensor do instituto. Em diversas ocasiões em que falou publicamente, o juiz chamou a atenção para o efeito de sensibilização que as audiências vinham surtindo sobre os magistrados. Em um evento realizado na Escola Paulista de Magistratura $(E P M)^{10}$, o juiz destacou que a prática diária das audiências vinha ajudando os magistrados a repensar a aplicação da prisão preventiva, especialmente diante do contato $^{11} \mathrm{e}$ do olhar mais próximo à realidade e às condições de vulnerabilidade da maior parte das pessoas presas. A notícia produzida pela assessoria de imprensa da EPM ${ }^{12}$ destacou estas colocações feitas pelo juiz à época:

Ele [Patiño] ressaltou a sensibilização provocada pela prática diária das audiências: "percebemos que o juiz deve amadurecer e dar um novo sentido ao que se espera de justiça. A reincidência, que era um mote para a decretação da prisão preventiva, perdeu um pouco da sua referência, assim como os rótulos dos crimes. Passamos a atentar para as qualidades do auto de prisão em flagrante, verificar com mais profundidade as situações e os dados

$10 \mathrm{O}$ evento correspondeu à aula inaugural do curso "Sistema carcerário brasileiro e Execução Penal" da EPM e aconteceu na sede da instituição, na cidade de São Paulo, no dia 7 de maio de 2017.

11 A questão da importância do contato entre juízes e custodiados nas audiências foi analisada por Gisi, Silvestre e Jesus (2019) e Toledo (2019).

12 Ver notícia: "EPM inicia o curso 'Sistema carcerário brasileiro e Execução Penal”, 13/06/2017. Disponível em: https://epm.tjsp.jus.br/Noticias/Noticia/44870 Acesso em: 04 ago. 2020. 
apresentados. No olho a olho, o juiz tem um potencial maior para fazer justiça, ainda que cautelar". E frisou a obrigatoriedade de o magistrado se fazer entender pela pessoa presa, lembrando que, ao menos a metade do contingente de presos é composta por indivíduos vulneráveis, sendo que $80 \%$ ou mais deles têm problemas com drogas: "são descamisados, drogados, doentes, semianalfabetos, nunca incluídos na sociedade, vários delesprimários", ressaltou. (ESCOLA PAULISTA DE MAGISTRATURA, 2017).

Outro aspecto bastante presente na gestão das audiências à época de sua implantação foi a abertura dada à pesquisa. $\mathrm{O}$ ex-corregedor autorizou a presença de pesquisadores acadêmicos e também ligados a organizações da sociedade civil que tinham interesse em acompanhar e levantar dados sobre o projeto. Não por acaso, logo nos primeiros anos de funcionamento das audiências de custódia em São Paulo, diversos relatórios de pesquisa foram produzidos (INSTITUTO DE DEFESA DO DIREITO DE DEFESA, 2016, 2017, 2019; CONECTAS, 2017; CNJ/FBSP, 2017), bem como teses e dissertações acadêmicas (JESUS, 2016; KULLER, 2017; BANDEIRA, 2020; TOLEDO, 2019).

As pesquisas produzidas naquele período, apesar de terem diferentes objetivos e fazerem uso de metodologias distintas, apontaram para uma conclusão comum: a ineficácia da audiência de custódia no combate à violência policial. É possível afirmar ainda, que esta constatação não era uma especificidade do contexto paulista, pois segundo um estudo de Ballesteros (2016), conduzido em âmbito nacional, a maior parte dos juízes e promotores dava pouca credibilidade aos fatos apresentados pelos presos e mais confiança à versão policial dos fatos. Especificamente no estado de São Paulo, o estudo de Jesus (2016) se debruçou sobre a crença de juízes e promotores na narrativa policial em caso de prisões em flagrante por tráfico de drogas. A autora observou que a fala dos policiais é frequentemente aceita por juízes e promotores sem questionamentos, além de ser apresentada por promotores e juízes como necessária para o próprio funcionamento do sistema de justiça. Com isso, práticas de violência, tortura ou ameaça raramente são averiguadas, já que não consideram verdadeiras as narrativas das pessoas presas, sobretudo aquelas acusadas por tráfico de drogas, expressões como violência policial, extorsão, flagrante forjado não aparecem nas deliberações de promotores e juízes (JESUS, 2016).

Essa ineficácia no combate à violência policial foi admitida pelo juiz ex-corregedor à época, em entrevista concedida ao Portal de notícias jurídicas JOTA ${ }^{13}$. Questionado sobre o processo de implantação das audiências e sobre os aspectos que precisavam de melhorias, o

13 Disponível em: https:/www.jota.info/justica/megaoperacao-reduz-qualidade-flagrante-e-pm-sp-precisa-de-novo-norte-13062016 Acesso em: 05 ago. 2020. 
magistrado afirmou:

Coisa negativa que podemos falar, sem rodeios, é que por hora não estamos obtendo resultado de uma das vertentes da custódia, que é apurar se houve maus-tratos ou tortura na prisão policial. Estamos engatinhando a passos pequenos de como fazer uma verificação aprofundada e qualificada dessa situação. E isso se dá por vários motivos: funcionários, estrutura e material. Estamos tentando dinamizar a corregedoria dos órgãos envolvidos na prisão. Se o preso fala que foi agredido, fazemos o apanhado e damos um procedimento para a corregedoria da polícia militar, ou à civil. Acontece que aguardávamos uma resposta mais rápida dessas instituições, mas caímos na falta de estrutura. Embora todas as corregedorias estejam esforçadas para cumprir o papel, não estão dando a resposta adequada. Como consequência, não estamos cumprindo essa vertente de identificar se houve desvio de agente estatal (JOTA, 2016).

Assim, fica evidente que o controle da violência policial sempre foi um ponto deficitário nas audiências de custódia, desde a sua implementação, e essa questão era publicamente tratada pela gestão anterior como uma deficiência que precisava ser aperfeiçoada. No entanto, o plano de seguir com o aperfeiçoamento foi interrompido no final de 2017, quando em eleição interna, os desembargadores do Tribunal de Justiça de São Paulo elegeram o seu novo presidente e corregedor-geral. O desembargador Geraldo Francisco Pinheiro, eleito Corregedor-Geral da Justiça para o biênio 2018/2019, convidou a então juíza da 2a Vara Criminal de São Paulo, Patrícia Álvares Cruz para assumir o cargo de corregedora do DIPO e, consequentemente, a coordenação das audiências de custódia. A indicação da referida juíza foi recebida com certa surpresa no meio jurídico e provocou reação entre os juristas considerados progressistas, já que a magistrada era conhecida pelo caráter rígido de suas decisões. Diversos textos foram publicados criticando a indicação de $\mathrm{Cruz}^{14}$, o que levou inclusive o Corregedor-Geral de Justiça recém-eleito a publicar um texto em defesa da magistrada ${ }^{15}$. O portal jurídico JOTA, ao noticiar ${ }^{16}$ a indicação da juíza, assim a descreveu:

Conhecida pelo rigor ao sentenciar, Patrícia Álvares Cruz ganhou as páginas dos jornais no começo dos anos 2000, quando condenou à prisão

14 Ver, por exemplo: https://www.jota.info/opiniao-e-analise/artigos/como-uma-nomeacao-pode-colocar-as-audiencias-de-custodia-em-xeque-20122017 e https:/www.jota.info/opiniao-e-analise/artigos/morte-das-audiencias-de-custodia-15122017 Acesso em: 04 ago. 2020.

15 Ver: https://www.jota.info/opiniao-e-analise/artigos/sobre-morte-da-audiencia-de-custodia-15122017. Acesso em: 04 ago. 2020.

16 Disponível em: https://www.jota.info/jotinhas/juiza-patricia-alvares-cruz-recebe-convite-para-assumir-o-dipo-em-sp-14122017. Acesso em: 06 ago. 2020. 
uma mulher chamada Maria Aparecida de Matos pela tentativa de furto de um xampu e um condicionador. Maria Aparecida foi vítima de tortura dentro da prisão e acabou perdendo a visão do olho esquerdo (JOTA, 2017).

Apesar das críticas recebidas por diversos juristas e organizações da sociedade civil, a juíza indicada assumiu a gestão do DIPO e das audiências de custódia na capital paulista no início de 2018. Ao tomar posse, a nova corregedora trocou toda a equipe de juízes do DIPO, compondo uma equipe de perfil mais conservador. O primeiro impacto dessa mudança foi percebido no resultado das audiências de custódia, com um aumento da manutenção da prisão provisória em detrimento de concessão de liberdades provisórias, com ou sem medidas cautelares. De acordo com dados do CNJ atualizados até junho de 2017, ano em que o juiz Patiño ainda estava como juiz corregedor do DIPO, do total de audiências realizadas em São Paulo, 46\% resultaram em liberdade provisória ${ }^{17}$. Em 2019, com a mudança na gestão, esse percentual passou a ser de $32 \%$ de liberdade provisória (INSTITUTO DE DEFESA DO DIREITO DE DEFESA, 2019) ${ }^{18}$. Não por acaso, interlocutores da pesquisa afirmaram que a indicação de Cruz se tratava de uma espécie de resposta dada pelo TJSP por sucessivas críticas internas relacionadas ao percentual de liberdade provisória praticada pelos juízes do tipo na gestão de Patiño.

A mudança na gestão das audiências também foi percebida pelas autoras deste texto no que se refere ao acesso e ao tratamento dado à pesquisa na custódia. Se na gestão anterior houve abertura e até mesmo incentivo à pesquisa e produção de dados nas audiências, com a mudança da gestão, as pesquisas passaram por uma série de obstáculos e restrições para obter autorização. A primeira dificuldade foi o acesso às audiências no período da manhã, isso porque o Fórum Criminal onde ocorrem as audiências é aberto ao público somente no período da tarde, sendo que pela manhã o acesso é permitido apenas a funcionários, operadores, advogados, estagiários e pessoas intimadas. As audiências de custódia começam pela manhã, por volta das 9 horas e seguem durante a tarde, após um intervalo para o almoço. Em 2019, foi solicitada à corregedora uma autorização para que as pesquisadoras pudessem acessar o Fórum pela ma-

17 Apesar do esforço para a implementação do SISTAC, conforme mencionado, a última atualização pública e oficial do CNJ sobre as audiências de custódia se deu em 2017, disponível em: https://www.cnj.jus.br/sistema-carcerario/mapa-audiencia-de-custodia/ Acesso em: 15 ago. 2020. O próprio CNJ reconhece que o sistema ainda está sendo montado e aperfeiçoado: https://www.cnj.jus.br/sistema-e-atualizado-para-melhorar-dados-sobre-audiencias-de-custodia/ Acesso em: 15 ago. 2020.

18 É importante ressaltar que, em diversos lugares do Brasil, as taxas de prisão provisória depois das audiências de custódia podem ser até maiores do que $65 \%$, como no caso de Porto Alegre, em que a prisão corresponde a $70 \%$ dos casos (INSTITUTO DE DEFESA DO DIREITO DE DEFESA, 2019, p. 106). Portanto, a importância de se pensar as audiências de custódia como confirmação do trabalho da polícia se dá por uma realidade não exclusiva da capital paulista. 
nhã e assim acompanhar as audiências ao longo do dia, autorização que já fora concedida para pesquisas anteriores. Contudo, a juíza não fez tal concessão e autorizou que os pesquisadores acompanhassem as audiências apenas no período da tarde, autorizando assim, aquilo já é de acesso público. Outras pesquisas recentes também relataram igual dificuldade de acesso e coleta de dados na segunda gestão, como proibição de realizar entrevista com os juízes e até mesmo de entrada nas salas de audiência (INSTITUTO DE DEFESA DO DIREITO DE DEFESA, 2019; TOLEDO, 2019; NEV/CEPID, 2020).

Outra importante mudança com a alteração da gestão do DIPO foi o encaminhamento dos casos de violência policial relatados nas audiências de custódia, que será analisado mais detidamente na próxima seção. Contudo, vale destacar aqui a concepção da atual corregedora em relação às denúncias de violência policial feitas em audiência. Em entrevista concedida ao portal jurídico Conjur ${ }^{19}$, a magistrada afirmou que o principal objetivo das audiências de custódia era a verificação de maus tratos no momento da prisão. No entanto, quando questionada se esse tipo de violência era uma constante, ela respondeu:

Óbvio que não sabemos exatamente o que aconteceu durante uma prisão, porque estamos distantes dessa prisão e da realidade policial. Mas é possível ter uma noção do que realmente houve ao analisar o exame de corpo de delito. É bem raro verificarmos lesões. Quando isso é ocorre, normalmente é porque o preso caiu durante a fuga ou resistiu à prisão. Há também casos de linchamento. Mas a quantidade de presos que alegaram violência policial para mim é enorme. Porém, em muitos casos, quando li o laudo não tinha absolutamente nada. Tem muita alegação infundada (CONJUR, 2018).

Ou seja, na concepção da magistrada, os laudos de exame de corpo de delito têm mais validade do que o depoimento de uma pessoa presa alegando a violência sofrida no momento da prisão. Além disso, segundo ela, muitas lesões registradas nos laudos se dão pela resistência à prisão ou tentativa de fuga, afirmando que existem ainda muitas alegações infundadas.

Outro ponto de inflexão na concepção das audiências por parte da atual gestão é a ideia de incidência sobre a criminalidade. Embora não faça parte dos seus objetivos, a ideia de tratar a audiência como um instrumento de segurança pública aparece na concepção da magistrada em um artigo publicado também no portal Conjur, no qual ela traça uma relação direta entre o aumento das prisões provisórias e a diminuição dos indicadores de criminalidade na capital paulista. A juíza alega que "[...] os índices de criminalidade da cidade de São Paulo, desde

19 Disponível em: https://www.conjur.com.br/2018-fev-18/entrevista-juiza-patricia-alvarez-cruz-chefe-dipo-sp Acesso em: 07 ago. 2020. 
janeiro de 2018, sofreram redução significativa, proporcional ao aumento de cerca de $20 \%$ no número de prisões preventivas, no primeiro semestre de 2018, comparado ao mesmo período do ano anterior" (CONJUR, 3 de setembro de 2019) ${ }^{20}$.

Diante deste contexto fica evidente a mudança não apenas nos procedimentos, mas também na concepção sobre as audiências de custódia e seus objetivos. A ideia de instrumento de segurança pública, com incidência sobre a dinâmica criminal, bem como a pouca credibilidade dada aos relatos de violência passou a compor a concepção sobre as audiências de custódia nesta nova gestão. Vale mencionar ainda que, no final de 2019, a juíza corregedora do DIPO foi mantida no cargo para o biênio 2020/21.

\section{ENCAMINHAMENTOS DOS CASOS DE VIOLÊNCIA POLICIAL: DUAS GESTOES DO DIPO}

A primeira gestão das audiências de custódia tinha como um dos principais desafios lidar com os relatos de violência policial, visto que havia grande expectativa de que essas audiências servissem como um espaço de apuração de abusos praticados por agentes, seja na abordagem, seja na delegacia. Um dos principais elementos nesse cenário foi o estabelecimento da regra de que os casos de violência policial mencionados em audiência de custódia seriam encaminhados ao DIPO 5: um cartório dedicado a receber exclusivamente procedimentos administrativos que dissessem respeito às atividades policiais e coordenado pelo juiz designado a ser "corregedor de polícias". O que aconteceu foi um verdadeiro encaixe na estrutura já existente, uma vez que o DIPO 5 já contava com uma estrutura inchada e abarrotada de procedimentos administrativos (BANDEIRA, 2020, p. 35).

O encaminhamento se dava da seguinte forma: após a menção explícita de que a pessoa havia sido fisicamente agredida por algum policial, a partir da pergunta de algum dos operadores que acompanhavam a audiência (embora a maioria das perguntas desse tipo fosse feita pelos juízes), o juiz determinava o encaminhamento ao Instituto Médico Legal para realização do exame de corpo de delito e enviava um ofício ao DIPO 5 contendo a mídia da audiência e o resultado do exame.

20 Disponível em: https://www.conjur.com.br/2019-set-03/opiniao-verdade-audiencias-custodia-sao-paulo Acesso em: 07 ago. 2020. 
Em pouco tempo, o termo "encaminhamento ao DIPO 5" passou a ser entendido como uma validação da narrativa da pessoa presa em audiência, ou seja, o reconhecimento, por parte do juiz, de que a versão da agressão precisaria ser investigada em procedimento próprio. No início das audiências, em 2015, o procedimento interno ao DIPO 5 era pouco conhecido para os próprios operadores, principalmente porque tal atribuição era nova para todos. Depois de alguns meses, o DIPO 5 passou a reencaminhar os procedimentos às Corregedorias de Polícia, que, por sua vez, passavam as denúncias de violência policial para serem apuradas na própria delegacia onde o flagrante havia sido lavrado, ou seja, funcionava como uma cortina de fumaça para o passa-e-repassa institucional que foi criado pelo TJSP (BANDEIRA, 2020, p. 147).

No entanto, algumas denúncias de violência chegaram a se tornar procedimentos investigativos: casos de violência física em que os exames de corpo de delito constataram lesão corporal viraram inquéritos, inclusive com audiências de reconhecimento de suspeitos, que eram realizados pelo juiz corregedor do DIPO 5 e com a participação do Grupo de Atuação Especial de Controle Externo da Atividade Policial (GECEP) do Ministério Público. Até onde se obteve informações, nenhum desses casos chegou a ser concluído com a responsabilização criminal de algum policial e a grande maioria foi arquivada antes de chegar até a instauração do inquérito ${ }^{21}$.

Apesar de parecer um encaminhamento pouco efetivo, alguns entrevistados disseram que na época em que os casos de violência policial eram enviados ao DIPO 5, aparentemente, houve um impacto na redução de relatos de agressão. No entanto, disseram não saber se realmente havia uma relação de causalidade, até porque poderia ser que os policiais tivessem adotado outros meios de não serem mais denunciados:

Eu tive um pouco essa percepção de que realmente a gente estava recebendo menos gente espancada, visivelmente espancada. E o número de relatos de tortura caiu, não a zero, evidentemente, mas menos que antes, é mais da metade dos presos, eles narravam violência policial, a grande maioria de forma bastante verossímil. [...] não tenho nenhum dado para demonstrar isso, então é uma percepção muito rasteira e que tem outras mil possibilidades, tem uma cifra oculta imensa. Os policiais podem esconder a tortura, não apresentando aquela pessoa para audiência de custódia, eventualmente matando aquela pessoa, ou então soltando depois da tortura. Então, enfim, não tenho como dizer isso, se há um efeito dissuasório ou não, parece que sim, mas nunca foram produzidos dados efetivamente em relação a isso (DEFENSOR 1).

21 De acordo com a pesquisa Blindando a Tortura (2017) da Conectas Direitos Humanos, dos 331 casos acompanhados em que houve relatos de violência, apenas $1 \%$ deles foram convertidos em inquéritos policiais. 
Essa percepção de que "não estava mais recebendo tanto preso arrebentado" foi compartilhada por outro defensor entrevistado. Antes desses encaminhamentos, os defensores recebiam "muito preso arrebentado e depois isso começou a diminuir e as denúncias de tortura começaram a cair" (DEFENSOR 4).

A prática da gestão anterior de encaminhar as denúncias de violência ao DIPO 5 também exercia uma pressão sobre o Ministério Público para que o órgão atuasse, de fato, no controle da atividade policial. Além disso, esse departamento tinha um papel importante de responsabilizar o Poder Judiciário a dar algum tipo de resposta ao caso, bem como um certo controle das providências adotadas, mesmo que tivessem como resultado o arquivamento.

Eu tinha as anotações de todos os casos em que foram reclamados os abusos, tinha expediente de todos esses casos, e combinei, de fato, com a Polícia Civil e a Polícia Militar para falar assim: - Olha, eu vou mandar cópia desse expediente, se o abuso era do eventual policial militar para a corregedoria da Polícia Militar, se era da Polícia Civil para a corregedoria da Polícia Civil, mas vou manter o expediente aqui. Para que? Para provocar o Ministério Público dele também exigir, através desse expediente, os outros expedientes formulados, seja no âmbito da Polícia Civil, seja no âmbito da Polícia Militar, seja na Guarda Civil (...) na constituição de 88 quem deve fazer o controle externo da atividade policial, leia-se Polícia Civil, Polícia Militar e agora também Guarda Civil, é o Ministério Público. Quem tem que assumir ou quem teria que assumir desde logo na audiência de custódia a verificação de eventual abuso, salvo o melhor juízo, seria o Ministério Público (JUIZ 1).

O entendimento de que compete ao Ministério Público a prerrogativa de apurar e acompanhar os casos de violência policial foi compartilhado por todos os entrevistados, ainda que a questão da tortura também seja uma preocupação da Defensoria Pública. No entanto, todos os defensores reafirmaram que o Ministério Público raramente exerce tal prerrogativa.

Então, a Defensoria, a violência policial afeta muito os pobres, exatamente o público da Defensoria, isso, inclusive, está na lei da Defensoria, da gente combater a violência policial, garantir o combate a isso, eu acho que seria o papel da Defensoria, de alguma forma, fazer isso. E o que ela faz, assim, de uma maneira não tão presente, é com o Núcleo de Direitos Humanos, mas eu entendo que o papel principal e ainda o mais central seria do Ministério Público, porque a gente ficar com a função ali de defender o custodiado e ainda acusar o policial, é uma função muito estranha. (DEFENSOR 1).

Um defensor disse que durante a audiência tenta chamar a atenção do promotor com relação à competência do MP de acompanhar e apurar os casos de violência narrados na audiência 
de custódia. Mais uma vez, o Ministério Público é destacado como sendo o órgão efetivamente responsável por apurar as denúncias de violência policial. De acordo com a posição dos entrevistados, é preciso pressionar, de alguma maneira, o MP para que o órgão assuma o efetivo papel que lhe foi conferido pela Constituição Federal de 1988.

A atual gestão rompeu com a prática de abertura de expediente no DIPO 5 e adotou o procedimento de oficiar as respectivas corregedorias de polícia, nos casos em que os juízes entendem como válidas as denúncias de violência no momento da prisão. Com o fim dos encaminhamentos ao DIPO 5, os entrevistados ressaltaram a perda do controle dos casos e de conhecimento do que é feito desses relatos de violência, que passaram a ser enviados diretamente às Corregedorias, sem a mediação de nenhum outro órgão do Departamento. Tornou-se mais difícil monitorar as denúncias. De certa maneira, o DIPO 5 funcionava como uma bússola do que era feito dos casos.

Paralelamente a essas mudanças, houve uma grande alteração no encaminhamento dos casos de violência envolvendo policiais militares. Em novembro de 2017, o então Presidente da República Michel Temer sancionou a Lei $n^{\circ}$ 13.491, que alterou a competência dos crimes militares, retirando da Justiça Comum e enviando à Justiça Militar a apuração de crimes cometidos por policiais militares durante o exercício de suas funções ${ }^{22}$. Essa lei alterou de forma substancial a competência da Justiça Militar, porque passou a incluir crimes que antes seriam processados e julgados pela Justiça Comum, o que gerou grande repercussão, inclusive com a propositura de duas Ações Diretas de Inconstitucionalidade já apresentadas ao STF que ainda não foram julgadas, mas que já receberam parecer favorável pela Procuradoria-Geral da República $^{23}$. Além de ferir explicitamente diversas convenções de Direitos Humanos dos quais o Brasil é signatário, a alteração legislativa enfraquece a possibilidade de controle das ações das polícias militares, principalmente porque foi direcionada a funcionar como sanção às atividades das Forças Armadas nas intervenções militares do Rio de Janeiro que ocorreram ainda no

\footnotetext{
22 A Lei 13.491 de 2017 alterou o Código Penal Militar, sucintamente, da seguinte forma: "Sempre que o autor do fato fosse um policial militar ou bombeiro e estivesse presente alguma das circunstâncias das referidas alíneas (em razão da atividade, do local e da vítima dos fatos), ao menos formalmente, estaria preenchido o requisito para conceituá-lo como crime militar impróprio, ainda que o tipo não estivesse descrito no Código Penal Militar", “Competência da Justiça Militar e Lei n 13.491/2017”, Centro de Apoio Operacional das Promotorias, Ministério Público do Paraná: http://www.criminal.mppr.mp.br/arquivos/File/Estudo_-_ATUALIZACAO_-_competencia_ da_justica_militar___versao_final.pdf Acesso em: 10 ago. 2020.

23 Em relação aos questionamentos quanto à Constitucionalidade da Lei, o art. $9^{\circ}$, inciso II, do CPM foi questionado nos autos da ADI n ${ }^{\circ} 5804 / \mathrm{RJ}$, enquanto o art. $9^{\circ}, \S 2^{\circ}$, é objeto da ADI n ${ }^{\circ}$ 5901/DF. Em ambas as Ações Diretas de Inconstitucionalidade, a Procuradoria-Geral da República se manifestou a favor da Ação, principalmente a partir do argumento de que a alteração representa uma grave ampliação da competência da Justiça Militar - Idem.
} 
Governo de Michel Temer ${ }^{24}$.

$\mathrm{Na}$ avaliação de um de nossos entrevistados "Quando [se] manda o informe direto para a Justiça Militar, na verdade se está excluindo a possibilidade de se apurar a tortura, porque tortura não é crime militar, tortura é crime comum, então quem pode apurar crime comum é a Polícia Civil". Para ele, o processo de encaminhamento feito atualmente resultou em "uma gambiarra" utilizada para que não haja denúncia de tortura (DEFENSOR 4).

$\mathrm{O}$ envio imediato dos relatos de violência envolvendo policiais militares à Justiça Militar possui um impacto significativo na forma como as audiências de custódia lidam com as denúncias em dois principais aspectos: o primeiro, na lógica processual que se cria e a conexão entre as instituições do sistema de justiça criminal; o segundo, no significado moral que essa transformação tem para o instituto como um todo.

Em relação às audiências de custódia de São Paulo, o efeito prático é que nenhuma instituição do Poder Judiciário toma conhecimento ou exerce qualquer papel sobre o procedimento, sendo que a notícia-crime foi feita na presença dos operadores do Direito que deveriam ser os principais responsáveis por apurar o cometimento dos delitos. Diante do perfil descrito da atual gestão do DIPO, houve uma acomodação entre o desinteresse em acompanhar os casos de tortura e averiguar o que é feito das denúncias após serem enviadas à Justiça Militar.

Já quanto ao aspecto simbólico das audiências, o envio à Justiça Militar deslegitima a as audiências de custódia como um mecanismo capaz de enfrentar a violência policial, uma vez que os próprios operadores passivamente "terceirizam" o trabalho para outros operadores que não têm os mesmos elementos de análise que a audiência presencial permite, como a realização de exame de corpo de delito em poucas horas após o relato da agressão. Sem esse mecanismo, toda a estrutura fica restrita à verificação dos aspectos formais e processuais que ensejam a conversão da prisão em flagrante em prisão preventiva, sem qualquer agência quanto às denúncias de tortura que podem surgir durante a audiência.

Além das mudanças com relação ao encaminhamento de casos de violência policial, outra questão refere-se à forma como os/as juízes/as da atual gestão do DIPO conduzem as audiências de custódia quando há relatos de abusos e tortura. Dados da pesquisa realizada pelo Núcleo de Estudos da Violência (NEV-USP) ${ }^{25}$ demonstram que há poucos questionamentos

24 A função da Justiça Militar deve ser, segundo "os sistemas internacionais de direitos humanos, a jurisdição militar há de ser (a) restrita (b) excepcional e (c) de competência funcional” - Ibidem, p. 11.

25 Pesquisadores do Núcleo de Estudos da Violência realizaram, entre os meses de outubro a dezembro de 2019 , pesquisa de campo nas audiências de custódia e os resultados preliminares constam no relatório científico do Núcleo (NEV/CEPID, 2020). 
sobre a violência e, quando ocorrem, o fazem em uma linguagem técnica, como ouvido com frequência pelos pesquisadores: "houve algum tipo de irregularidade no momento da prisão?" Sem questionar de forma explícita se a pessoa sofreu agressão, os juízes, muitas vezes, levam à incompreensão por parte do custodiado.

Essa diferença entre a forma que os juízes da primeira gestão das audiências de custódia questionavam supostas agressões policiais com relação à segunda foi evidenciada na fala dos nossos entrevistados, que destacaram que no primeiro grupo havia uma preocupação maior com os relatos de violência policial do que no segundo:

[...]talveznaépoca[daantigagestão]porserumcomeçodaaudiência,eles[juízes] tinham a preocupação um pouco maior de apurar violência, eles ficavam com mais receio de deixar as violências passarem, na dúvida eles acabavam optando por investigar mais coisas do que agora é feito, agora é muito mais difícil extrair qualquer tipo de providência do judiciário, ainda que seja uma investigação que não passa pelo DIPO 5, mas que seja ação na Corregedoria (DEFENSOR 1).

$\mathrm{Na}$ atual gestão, os entrevistados disseram que muitos juízes deixam de perguntar aos custodiados qualquer aspecto relacionado a possíveis agressões sofridas no momento da prisão por agentes policiais. Destacaram a atuação de uma juíza em particular, que sempre perguntava sobre situações de violência que a pessoa presa poderia ter sofrido, e nos casos afirmativos, fazia perguntas específicas. Contudo, destacaram que talvez ela tivesse essa postura diferenciada por ser uma juíza destacada à função de corregedora das polícias:

Então, o que eu percebo é que a [juíza X] faz a audiência com uma conduta muito mais zelosa com relação a essa matéria. Então alguém relata alguma violência. Em primeiro lugar ela não faz chacota, ela fala: - Que tipo de violência? Ela pode nem estar gostando do que o cara está falando, mas ela fala: - Qual foi o tipo de violência? Onde foi? Aonde foi a agressão? Essa agressão foi chute, foi tapa, foi soco? Você tem condições de reconhecer essa pessoa? Quais são as características dela? Aí a pessoa fala: - Ah, é um baixinho. - Baixinho é muito genérico, o que é baixinho? Aí a pessoa fala meio com relação à altura dele, sei lá. Ah, cor de pele, tinha cabelo? Que cor de cabelo? Entendeu? Você percebe que ela faz mais perguntas para dar embasamento. Alguns juízes não fazem pergunta nenhuma e alguns juízes fazem perguntas bem mais genéricas (DEFENSOR 2).

Outro entrevistado disse que essa mesma juíza anotava tudo o que a pessoa presa relatava da violência policial no termo da audiência para encaminhar o ofício com o maior número de informações possíveis. Contudo, conforme apontado pelos entrevistados, o procedimento ado- 
tado por essa magistrada é exceção. Raramente, os demais juízes fazem os mesmos encaminhamentos, o que demonstra a ausência de atuação padronizada dos juízes nos casos de relato de violência policial. Pode-se, portanto, afirmar que parte dos magistrados paulistanos não segue a Resolução $n^{\circ}$ 213/2015 do Conselho Nacional de Justiça, que recomenda o questionamento explícito sobre agressões e maus-tratos no momento da prisão.

Os defensores entrevistados também reforçam essa constatação, destacando que muitas vezes é a Defensoria que precisa fazer o questionamento sobre possível violência policial quando as pessoas presas chegam machucadas, porque os juízes não o fazem. Contudo, destacaram que é complicado para o defensor da ponta fazer esse tipo de atuação pois:

Para os defensores que estão ali na ponta é muito difícil, para a gente, incriminar
pessoas, como a gente está na linha do dia a dia da defesa, é difícil, por mais que
seja a questão da violência policial, dar ensejo a ações penais não é da nossa
natureza isso. E a gente acha que na ponta faz muito sentido o Ministério Público
assumir essa responsabilidade, porque ele é o órgão acusador por excelência,
no nosso ponto de vista, pelo menos no meu ponto de vista, competiria ao
Ministério Público verificar se realmente há abuso policial (DEFENSOR 2).

Ainda de acordo com os relatos dos entrevistados, a questão da violência policial não deve ser o foco de preocupação da defesa, porque tanto para o defensor quanto para o custodiado, a questão mais urgente na audiência de custódia é a obtenção da liberdade.

Outra questão com a qual a pesquisa se deparou foi a da suspensão das audiências de custódia, desde o mês de março de 2020, devido à pandemia de Covid-19. O impacto mais imediato se deu sobre a apreciação presencial da prisão em flagrante e também sobre os relatos de violência. Desde o início da pandemia, os juízes vêm apreciando os flagrantes de forma documental, como era feito antes da implementação das audiências, sem ver e ouvir os custodiados sobre as circunstâncias da prisão. Nesse mesmo período, também têm sido recorrentes as denúncias de violência policial, especialmente nas áreas periféricas da capital, geralmente gravadas e divulgadas nas redes sociais e mídia em geral. Os dados oficiais também apontam o aumento significativo da ocorrência de mortes em decorrência da intervenção policial (MDIP) de março a novembro de 2020. De acordo com os dados da Secretaria de Segurança de São Paulo, houve um crescimento de $21 \%$ do número de pessoas mortas pela polícia no primeiro semestre de 2020, em comparação com o mesmo período de 2019. As polícias Civil e Militar vitimaram 514 pessoas em supostos tiroteios, durante o serviço e também durante a folga, de janeiro a junho. É o maior número da série histórica do governo paulista, que iniciou em 2001. Em relação à Polícia Militar, foram 435 pessoas mortas por agentes em serviço em 2020 contra 
358 do ano passado. Também cresceu o número de vítimas de policiais militares de folga. Em 2019, foram 56 e passaram no ano seguinte a 63. Isso acontece justamente em um momento de redução de indicadores criminais ${ }^{26}$.

Ainda no mesmo período de suspensão das audiências em 2020, os casos de violência policial no estado de São Paulo tornaram-se públicos com a divulgação de vídeos nas redes sociais. Não é possível estabelecer uma relação de causalidade entre essa visibilidade dos casos de agressões policiais com a interrupção das audiências de custódia. Porém, é possível que as audiências sejam um fator inibidor da violência policial e que, em decorrência de sua temporária suspensão, haja um aumento de ocorrências de abuso do uso da força, ainda que na prática não sejam efetivas com relação à apuração de denúncias, já que os relatos, quando recebidos, são meramente encaminhados às Corregedorias das polícias e nenhum tipo de monitoramento ou controle desses casos é realizado pelo Poder Judiciário.

Desse modo, é possível supor que a interrupção das audiências tenha, de alguma forma, influenciado o crescimento da violência policial, já que o efeito inibidor e dissuasório das audiências também teria sido suspenso, mas por ora os dados não permitem o aprofundamento desta análise.

\section{CONSIDERAÇÕES FINAIS}

Se as audiências de custódia tinham como um dos seus objetivos centrais a apuração de violência policial, é possível questionar o quanto elas se aproximaram desse objetivo a partir da forma com que as gestões se organizaram para acolher e processar os relatos dos presos, ou que tipos de mecanismos foram criados para levar esses relatos adiante, naquilo que pode ser considerado "pós-audiências". Privilegiar esse ponto de análise não significa que outros fatores das audiências sejam menos importantes, como a efetiva diminuição das prisões provisórias ou o encaminhamento feito aos casos de pessoas com dependência química e em situação de rua, mas significa que as respostas institucionais para os relatos de violência refletem objetivamente qual o peso ou a importância que as audiências têm como mecanismo de apuração de tortura policial.

26 Dados divulgados pela Secretaria de Segurança Pública de São Paulo e noticiados no Portal do G1. Disponível em: https:/g1.globo.com/sp/sao-paulo/noticia/2020/07/25/mortes-cometidas-pela-policia-militar-de-sp-crescem-21 percent-no-primeiro-semestre.ghtml Acesso em: 13 ago. 2020. 
Nesse sentido, pelo que foi relatado nas entrevistas com os operadores e pelas pesquisas que se debruçaram sobre o tema ao longo dos últimos cinco anos, as denúncias de violência policial feitas em audiências de custódia não foram apuradas, seja porque o próprio DIPO 5 não conseguiu provocar suficientemente as outras instituições a se mobilizarem para o tema, seja porque agora os relatos são enviados diretamente às Corregedorias de Polícia ou à Justiça Militar e saem do controle do Poder Judiciário. Não se tem notícia de nenhum caso em que os agentes de segurança tenham sido investigados e responsabilizados depois das audiências, mas sim a ocorrência de um arquivamento em massa, neutralizando o papel das audiências como oportunidades de se coletar os nomes ou características de policiais que tenham descumprido com seus deveres de segurança.

É importante ressaltar que todos os entrevistados relembraram a obrigação constitucional do Ministério Público de atuar como controlador da polícia e que o descumprimento desse dever é ainda mais nítido em uma audiência em que o promotor está presente e ouve, em primeira mão, uma denúncia de violência policial. A oportunidade de agir está dada não só com o relato mais recente, com detalhes físicos e emocionais que podem ser coletados com qualidade dentro do prazo de 24 horas, mas também porque há ali a possibilidade de coletar outras informações relevantes, como o nome dos policiais responsáveis pela prisão, do delegado, a delegacia responsável e outros dados que permitiram uma investigação mais apurada, seja porque estão escritas no próprio auto de prisão, seja porque a pessoa sabe dessas informações.

Da mesma forma, o juiz que conduz a audiência também poderia exercer um papel mais efetivo nessa função, dado que é de responsabilidade do magistrado fazer perguntas referentes à possibilidade de ter havido violência, conforme a diretriz da Resolução 213 do CNJ, em vigência desde 2015. Ainda que se alegue que a responsabilidade de processamento passa a ser de outra instituição, a própria coleta do relato completo faz parte das obrigações desses juízes compreendidas pelo próprio $\mathrm{CNJ}$ e não devem ser prescindidas apenas porque o restante da investigação deixa de ser da competência deles. As mesmas condições de oportunidades de apuração que são dadas ao promotor, são dadas aos juízes, que devem zelar pelo melhor atendimento às regras de proteção individual à pessoa.

O que parece acontecer é uma acomodação das audiências como uma fase pré-processual, que cumpre mais uma função de apenas verificar as condições da prisão do que de considerar a palavra da pessoa presa em flagrante, seja quanto aos detalhes dos fatos, seja quanto a uma possível ocorrência de violência policial. A presunção de veracidade do documento policial é tamanha, que mesmo com a presença física da pessoa, os operadores ficam condicionados a levar em consideração o que é relatado no documento do auto de prisão e sequer realizam 
perguntas que poderiam ser muito mais esclarecedoras, em um processo de "escuta seletiva" (BANDEIRA, 2020, p. 134). Com isso, ou já se presume que a versão da pessoa presa é inverídica, ou que a versão narrada pela polícia é a única dotada de verdade e é desnecessária a confrontação entre as narrativas.

Outro ponto importante que merece destaque é a singularidade do lugar das audiências na capital paulista: o DIPO. O desenho institucional do poder judiciário paulista prevê que a Corregedoria-Geral de Justiça indique o corregedor do DIPO que, por sua vez, fará a seleção dos juízes que compõem o departamento. Tal estrutura facilita a orientação e o alinhamento político dos magistrados com o corregedor do DIPO, e consequentemente, com a presidência do Tribunal de Justiça. A falta de transparência nesse processo de indicações diretas, bem como o descumprimento de uma lei que, desde 2013 estabelece critérios mínimos para a indicação dos juízes do DIPO, deixa visível o controle exercido pelo Tribunal de Justiça e o uso que tem sido feito do Departamento, afastando ainda a possibilidade dos juízes decidirem com base no princípio do livre convencimento. Com a implantação das audiências de custódia no DIPO, este controle político ficou ainda mais evidente, especialmente com a mudança de gestão em 2018 e seus resultados.

Com a atual coordenação, parece ter havido uma mudança na percepção sobre qual é o objetivo central das audiências de custódia. Ao associar a redução de certos indicadores criminais ao aumento da manutenção das prisões provisórias, assume-se que as audiências servem como um instrumento de controle da criminalidade e passa-se a compreender o juiz como um operador da segurança pública. No que diz respeito às denúncias de violência e maus-tratos sofridas durante a prisão, as duas gestões se mostraram incapazes de criar mecanismos eficazes ao enfrentamento do problema, muito por conta da inércia do Ministério Público em assumir sua função de órgão controlador. No entanto, se na primeira gestão havia uma preocupação mínima em pressionar tanto as corregedorias quanto o próprio Ministério Público, na segunda gestão, na qual a ideia da audiência incidindo sobre a criminalidade ganhou espaço e desconfiança diante dos relatos de violência impera, a preocupação em exercer qualquer controle sobre a violência policial praticamente desaparece. O que a comparação entre as duas gestões deixa evidente são os limites do instituto das audiências de custódia diante da visão que cada um desses gestores tem tanto sobre a política criminal quanto sobre a finalidade da audiência em si, somado ainda ao arranjo político institucional do poder judiciário local.

Por fim, a suspensão das audiências de custódia e a volta dos procedimentos decisórios efetuados novamente em formato de papel parece sinalizar que o sistema de justiça se acomodou rapidamente ao modelo anterior às audiências de custódia, o que revela, sobretudo, a pouca 
importância dada aos possíveis casos de violência policial e a relativa centralidade dessa questão como prerrogativa da avaliação dos autos de prisão em flagrante. A ausência das fotos e os pedidos protocolares feitos pelos juízes, meramente burocráticos, evidenciam a descaracterização do papel da audiência de custódia em ser um espaço de escuta dos relatos, encaminhamento dos casos e inibidor dessas práticas de violência policial.

\section{REFERÊNCIAS}

1. BANDEIRA, Ana Luiza Villela de Viana. Audiências de custódia: percepções morais sobre violência policial e quem é vítima. Belo Horizonte: Casa do Direito, 2020.

2. BALLESTEROS, Paula R. Audiências de custódia e prevenção à tortura: análise das práticas institucionais e recomendações de aprimoramento. Relatório de Pesquisa, Departamento Penitenciário Nacional. Brasília, 2016. 63 p. Disponível em: https://bit. ly/36cDQCm. Acesso em: 18 mar. 2020.

3. CONECTAS. Tortura blindada: como as instituições do sistema de justiça perpetuam a violência na audiência de custódia. São Paulo, 2017. Disponível em: https://www. conectas.org/publicacoes/download/tortura-blindada. Acesso em: 05 abr. 2021.

4. CNJ/FBSP. Direitos e garantias fundamentais: audiência de custódia, prisão provisória e medidas cautelares: obstáculos institucionais e ideológicos à efetivação da liberdade como regra (DPJ/CNJ). 2018. Disponível em: http://www.forumseguranca.org.br/ wp-content/uploads/2018/01/FBSP_Direitos_Garantias_Fundamentais_Audiencia_ Custodia_2017_Sumario.pdf. Acesso em: 05 abr. 2021.

5. ESCOLA PAULISTA DE MAGISTRATURA. Aula inaugural do curso "Sistema carcerário brasileiro e Execução Penal”. São Paulo, 7 de maio de 2017.

6. GARCIA, Gabriel Mendes. Audiência de custódia e o encarceramento em massa de minorias. Trabalho de Conclusão de Curso (Graduação em Direito) - Universidade Presbiteriana Mackenzie, São Paulo, 2020.

7. GISI, Bruna; JESUS, Maria Gorete; SILVESTRE, Giane. O contato com o público importa? Plural, v. 26, n. 2, p. 247-270, 2019. Disponível em: https://www.revistas.usp. br/plural/article/view/165683. Acesso em: 18 mar. 2020.

8. INSTITUTO DE DEFESA DO DIREITO DE DEFESA. Audiências de custódia. Panorama Nacional. [s.1.: [s.n.], 2017. Disponível em: http://www.iddd.org.br/wpcontent/uploads/dlm_uploads/2017/12/sumarioexecutivo_web2.pdf. Acesso em: 05 abr. 2021. 
9. INSTITUTO DE DEFESA DO DIREITO DE DEFESA. Monitoramento das audiências de custódia em São Paulo. [s.1.: s.n.], 2016. Disponível em: http://www. iddd.org.br/wp-content/uploads/2016/05/relatorio-ac-sp.pdf. Acesso em: 05 abr. 2021.

10. INSTITUTO DE DEFESA DO DIREITO DE DEFESA. O fim da liberdade: a urgência de recuperar o sentido e a efetividade das audiências de custódia. [s.1.: s.n.], 2019. Disponível em: https:/www.cnj.jus.br/wp-content/uploads/conteudo/arquivo/2019/09/ bf7efcc53341636f610e1cb2d3194d2c.pdf. Acesso em: 05 abr. 2021.

11. JESUS, Maria Gorete Marques de. "O que está no mundo não está nos autos": a construção da verdade jurídica nos processos criminais de tráfico de drogas. 2016. Tese (Doutorado em Sociologia) - Faculdade de Filosofia, Letras e Ciências Humanas, Universidade de São Paulo, São Paulo, 2016.

12. KULLER, Laís Bóas Figueiredo. Audiências de custódia: um ponto de inflexão no sistema de justiça criminal? 2017. Dissertação (Mestrado) - Programa de PósGraduação em Ciências Humanas e Sociais, Universidade Federal do ABC, São Paulo, 2017.

13. KANT DE LIMA, Roberto. A polícia da cidade do Rio de Janeiro: seus dilemas e paradoxos. Rio de Janeiro: Forense, 1995.

14. MISSE, Michel et al. O inquérito policial no Brasil: uma pesquisa empírica. Rio de Janeiro: NECVU/IFCS/UFRSJ; BOOKLINK, 2010.

15. NEV. Center for the Study of Violence University of São Paulo. Cepid Fapesp Program. Building Democracy Daily: Human Rights, violence and institutional trust. 7th. Report. São Paulo, 2020.

16. PAES, Vívian Gilbert. Crimes, procedimentos e números: estudo sociológico sobre a gestão dos crimes na França e no Brasil. Rio de Janeiro: Garamond, 2013.

17. SILVESTRE, Giane; JESUS, Maria Gorete de; BANDEIRA, Ana Luiza Villela de Viana. Pandemia, prisão e violência: os efeitos da suspensão das audiências de custódia na cidade de São Paulo. Dilemas: Revista de Estudos de Conflito e Controle Social, Rio de Janeiro, Texto 64, p. 1-12, 2020. Disponível em: https://www.reflexpandemia. org/texto-64. Acesso em: 05 abr. 2021.

18. TOLEDO, Fabio Lopes. "O flagrante ganha voz?": os significados da presença da pessoa presa nas audiências de custódia no estado de São Paulo. 2019. Dissertação (Mestrado) - Fundação Getulio Vargas, Escola de Direito de São Paulo, São Paulo, 2019.

Giane Silvestre

Doutora em Sociologia pela Universidade Federal de São Carlos. Pesquisadora de pósdoutorado no Núcleo de Estudos da Violência da Universidade de São Paulo. Pesquisadora 
do Grupo de Estudos em Violência e Administração de Conflitos e do Instituto de Estudos Comparados em Administração de Conflitos. ID ORCID: https://orcid.org/0000-0002-86398843. E-mail: silvestregiane@usp.br. Colaboração: pesquisa bibliográfica, pesquisa empírica, análise de dados, redação e revisão do texto.

Maria Gorete Marques de Jesus

Doutora em Sociologia pela Universidade de São Paulo. Pesquisadora do Núcleo de Estudos da Violência, Pós-doutoranda do Departamento de Sociologia da Universidade de São Paulo. ID ORCID: https://orcid.org/0000-0003-2667-8736. E-mail: goretim@usp.br. Colaboração: pesquisa bibliográfica, pesquisa empírica, análise de dados, redação e revisão do texto.

Ana Luiza Villela de Viana Bandeira

Doutoranda pela Escola de Direito da Fundação Getúlio Vargas de São Paulo, Mestre em Antropologia Social pelo Departamento de Antropologia Social da Universidade de São Paulo. ID ORCID: https://orcid.org/0000-0002-9868-7706. E-mail: analuiza.bandeira12@gmail.com. Colaboração: pesquisa bibliográfica, pesquisa empírica, análise de dados, redação e revisão do texto. 